Persp. Teol. 37 (2005) 225-237

\title{
O PUDOR COMO PASTOR DO SER: REFLEXÕES SOBRE A SEXUALIDADE EM CHAVE PERSONALÍSTICA
}

\author{
Massimo Pampaloni SJ \\ O amor ama o mistério, \\ O amor ama o silêncio.
}

(S. Kierkegaard)

RESUMO: Partindo de uma reflexão fenomenológica em chave personalística, o autor propõe a leitura do pudor em duas direções fundamentais. Por um lado, o pudor intervém em situações de "crise", revelando um lado obscuro do eros. Por outro lado, ele não se limita a ser um "freio" ou um "sinal de perigo", antes revela o outro e o si mesmo como não redutíveis a puro-objeto-de prazer. Assim, retira do ser-outro o véu da objetivação à qual é reduzido quem é objeto de um olhar despudorado. Nesse sentido, o autor propõe, contra a concepção banal e redutiva da sexualidade, uma resgate do pudor próprio como guardião e pastor do núcleo irredutível da pessoa e de sua dignidade.

PALAVRAS-CHAVE: pudor, sexualidade, personalismo, Soloviev, Wojty ${ }^{3}$.

ABSTRACT: From the perspective of a phenomenological reflection in a personalist approach, the author proposes an interpretation of pudency in two fundamental directions. On the one hand, modesty intervenes in situations of "crisis", revealing the dark side of eros. On the other hand, it is not a "brake" nor a "signal of 
danger", but rather it reveals the other and the self as not limited to a purelypleasure-object. So, it takes away the veil of objectification from the other-being who was reduced to an object of a wanton stare. In this sense, against a banal and reductive conception of sexuality, the author proposes a retrieval of self pudency as a guardian and shepherd of the person's irreducible core and dignity.

KEY-WORDS: pudency, sexuality, personalism, Soloviev, Wojtyª.

\section{Introdução}

- $\mathrm{m}$ uma entrevista publicada há algum tempo no caderno "Folha ilusEtra-da", a atriz Angelina Jolie, à pergunta sobre o que pensava do fato que a imprensa a vivesse classificando ora como gay, ora como bissexual, ora como heterossexual, respondeu:

Não há nada de errado com nenhum desses rótulos. Você ama a pessoa que ama, não importa sexo, idade ou cor. Amor é atração, é a transa perfeita, como a que tenho com meu marido. Eu encontrei o amor da minha vida, e ele é um homem. Mas poderia ter sido uma mulher, porque, por mais de uma vez, já estive apaixonada por uma mulher. Não entendo como uma coisa bonita como o amor pode ser polêmica. ${ }^{1}$

Esta afirmação de Jolie pode ser apresentada como um ótimo exemplo de des-pudor, além de ser exemplo de confusão mental, típica da mentalidade mass-medial. $\mathrm{O}$ amor aqui é reduzido exatamente ao que Soloviev chamaria de "degradação inferior", contra a qual exatamente o pudor é que nos alerta, nos protege e nos indica o caminho correto.

Tal confusão encontra-se, hoje, na base de qualquer discurso sobre esse tema. Perguntamo-nos se não poderia ser útil refletir sobre a virtude do pudor, como uma possibilidade de resgatar um "discurso-outro" a respeito da sexualidade e, já que a sexualidade apresenta-se como âmbito fundamental de crescimento, expressão e vida mesma do ser humano, poderíamos receber dela importantes ensinamentos também para outros âmbitos da nossa existência.

De fato, mais do que outras virtudes, o pudor parece ser expontaneamente compreendido como virtude "habitual", ao lado - precisamente - do eros. Onde quer que haja um eros, aparece uma forma de pudor. Pode-se falar de um pudor da mente que enfrenta um problema ou um texto, um pudor do nosso quotidiano ao interpelarmos os outros, ao tomarmos um objeto, ao apresentar-nos ao olhar de outrem, porque também lá existe um eros.

\footnotetext{
${ }^{1}$ Entrevista recolhida por M. LACOMBE, "Tomb Rider. O cinema em jogo" in Folha de São Paulo, 14/06/01, p. E1.
} 
Veremos que, contudo, o pudor remete a situações particulares de crise: especialmente lá onde não se pode não ignorar, nem mesmo tematicamente, o nosso eros e a sua escuridão².

Procederemos, portanto, da seguinte maneira. O pudor intervém em situações de "crise". Reconheceremos, na sexualidade, um lado "escuro", problemático. O pudor, manifestando-se em tais situações, por um lado as "revela" e, por outro, age como um guardião, protegendo-nos delas. Mas o pudor não age somente como indicador de "perigo", ao contrário, revela a positividade daquilo que somos e manifesta e oferece o caminho para o amor autêntico. Nesse sentido, o pudor pode ser chamado de verdadeiro "pastor do ser": guia, protege e indica verdes pastos e águas tranqüilas junta às quais repousar.

Em nosso breve reconhecimento, escolhemos como guias alguns nomes que marcaram a filosofia personalística: E. Mounier, V. Soloviev, K. Wojtyª. Nosso trabalho quer ser uma espécie de saudade dos tempos em que se pensavam as coisas, quando ainda não existia o proton pseudos do pensamento (se é que ainda é pensamento) hodierno, ou seja, esquecimento, se não desconfiança, da capacidades da razão, a redução da razão a instrumento secundário com relação aos "sentimentos": sentimentos que são, porém, o fruto de uma confusão mental, a qual, mais do que encerrar-nos em um "simples" Erlebnis de tipo heideggeriano, encerra-nos na animalidade que não-somente-somos, mas que, vivendo de maneira despudorada, sempre nos aguarda em um abraço mortal.

Acreditamos que seja perfeitamente possível, por meio de ações prévias de ecologia mental, propor estas reflexões para uma educação sexual que seja verdadeiramente tal, ao ponto de restituir à sexualidade seu status de lugar "soteriofânico".

\section{A sexualidade é um mistério}

Um belo texto de P. Ricoeur compreende a sexualidade como enigma, reconhecendo-lhe um caráter "impermeável à reflexão e inacessível ao domínio humano", e exatamente por isto representável somente simbolicamente ${ }^{3}$.

Retomamos, mais ou menos, o mesmo conceito, usando outras categorias. Preferimos falar antes de mistério do que de enigma. Enigma é algo que tem uma solução, ainda que escondida, difícil, arcana (o enigma da Esfinge). O mistério, ao contrário, é algo que supera, que é "outro", que é

${ }^{2}$ G. NARDONE, Etica Generale, (apostila para uso dos estudantes), Istituto di Studi Filosofici Aloisianum, Padova, 1997/98, versão eletrônica, passim.

${ }^{3}$ Cf. P. RICOEUR, "A Maravilha, o Descaminho, o Enigma", Paz e Terra 5 (1967) 36. 
impenetrável: não somente porque nos faltam os meios para fazê-lo, mas porque por sua própria natureza é indisponível. Cremos, contudo, que Ricoeur entenda enigma mais neste sentido do que no primeiro.

Diante de um texto como o de Jolie, que apresentamos na abertura do nosso artigo, reage-se, justamente (caso se reaja!), diante da banalização e da confusão que é feita entre sexualidade e amor, identificando-os em um todo indistinto.

Mas há também um outro perigo no qual se cai hoje com a maior facilidade. É o de ver na sexualidade somente o lado "solar", o lado "normal". É esquecida a complexidade do fenômeno, o duplo aspecto do eros. Onde quer que haja um eros, há um lado "obscuro", um lado que nos coloca em perigo, que pode reduzir-nos totalmente a algo que somos, mas que nos envergonhamos de ser, caso fôssemos identificados somente com ele.

Em todas as culturas de todos os tempos, a sexualidade foi sempre percebida como algo "especial" e sempre foi coberta (diríamos com "pudor") de sacralidade e de ritos.

Um exemplo interessante podemos encontrar no mundo grego. K. Jaspers ${ }^{4}$ faz notar como, para os gregos, tudo que era relativo à sexualidade era dividido, por assim dizer, em quatro Deusas: Era, que protegia o matrimônio; Afrodite, que enobrecia a esfera da sexualidade, elevando-a à beleza; Artêmis, a virgem dos bosques, que guardava os limites e as fronteiras, e, não por acaso, a sexualidade; e, por fim, Deméter, a força infinita da fertilidade, mas também da destruição (está relacionada misteriosamente ao Hades, à morte). Cada uma destas deusas representa um dos aspectos do mesmo fenômeno complexo. A necessidade de identificá-lo com uma multiplicidade de figuras parece exatamente indicar uma evidente impossibilidade de unificação.

Jaspers cita ainda Demóstenes ${ }^{5}$, que descreve os costumes de seus concidadãos, para os quais as jovens hetairas existem para que eles se divirtam e se recreiem; as prostitutas, para satisfazer sua necessidade física; e as esposas, para que tenham filhos legítimos, ordenem e mantenham a própria casa. Compreendendo o texto na perspectiva da época, uma vez mais emerge a dificuldade de unificar "exigências" diferentes que requerem figuras diferenciadas e rigidamente separadas. Tudo gira ao redor do mesmo campo, mas tudo "não-se-pode" pôr junto.

Acreditamos que, não por acaso, em uma obra de Jean-Pierre Vernant ${ }^{6}$, encontramos, sob outro ponto de vista, três figuras principais do divino grego que se apresentam "mascaradas", i. é, das potências da experiência

${ }^{4}$ K. JASPERS, Piccolo corso di filosofia, Milano: Edizioni di Comunità, 1968, pp. 118s. ${ }^{5}$ DEMÓSTENES, In Nearia, p. 122.

${ }^{6}$ J.-P. VERNANT, La morte negli occhi. Figure dell'Altro nell'antica Grecia, Bologna: Il Mulino, 1987. 
da Alteridade que os gregos elaborarão, há duas relacionadas diretamente com o sexo: Dionísio e Artêmis (a orgia e a castidade: ambas as figuras relacionadas com a iniciação). A terceira é Medusa, a alteridade absoluta, a morte.

O mundo que faz referência ao sexo é, portanto, relacionado a algo "obscuro", misterioso: tremendum, diríamos. O que, portanto, entra em jogo neste terreno que o pudor "revela"?

\section{O pudor age em situação de "crise"}

Notávamos, na introdução, como se fala de pudor cada vez que se tem um eros: pudor da mente, pudor no manifestar sentimentos, etc. Mas, essencialmente, o pudor está relacionado ao campo da sexualidade, mesmo que, como Soloviev demonstra, na realidade ele perpasse todos os âmbitos da pessoa7. Ele age quando meu eros é algo cujo caráter "obscuro" não pode ser ignorado.

A Escritura pareceria mostrar um nexo entre pudor e sentido do pecado. O pudor revelar-se-ia como conseqüência necessária da "perturbação" determinada pela culpa na profundidade íntima da pessoa: "diante da incapacidade do ser humano de exercitar um pleno controle sobre si mesmo, de dominar completamente as próprias paixões, o pudor aparece como o "guardião do ser"8. O episódio de Noé $($ Gn 9,22) mostra como o pudor não esteja relacionado apenas à proteção da esfera sexual na condição anterior à queda. Mostra que o pudor tende também a delimitar uma zona de inviolabilidade, como diria Wojty ${ }^{3}$, da pessoa mesma. Diz ainda Campanini: "Tanto o Antigo Testamento quanto o Novo Testamento (...) têm em geral uma visão serena e equilibrada da corporeidade e da sexualidade. A ostentação impudica do próprio corpo e a nudez mesma são condenadas, não por causa de uma radical rejeição da corporeidade, mas para impedir que ela, reduzida a objeto da paixão, seja assumida fora de um contexto de amor e de doação, e, portanto, de reciprocidade" ${ }^{\prime \prime}$.

Sucessivamente, esta visão realista e serena ao mesmo tempo, foi sendo obscurecida e explodiu uma reação contrária negativa a qualquer idéia de pudor. Sobretudo a partir do séc. XVIII, houve como que uma inversão da

\footnotetext{
${ }^{7}$ Isto poderia ser, na nossa opinião, um sinal da importância absolutamente específica da sexualidade no campo da pessoa humana, não redutível absolutamente a "apenas" uma função biológica.

${ }^{8}$ G. CAMPANINI, "Pudore", in Il cristiano fedele alla terra. Contributi ad una "teologia del mondo", Bologna: EDB, 1984, p. 210.

${ }^{9}$ Ibidem, p. 211.
} 
situação em todos os campos, acabando por afetar também o nosso tema. Desde então, diversas posições negativas sucederam-se e, no fundo, estão na base da hodierna concepção "vulgar" do pudor. Esta vê o pudor como uma "invenção do amor e da volúpia refinada" uma espécie de "jogo erótico" (Helvetius, Diderot, etc.), a qual reduz o pudor a simples dado cultural, uma negação do inatismo típica de algumas escolas psicológicas, chegando à psicanálise, que vê no pudor uma força de inibição da libido. Mas a negação mais séria, na nossa opinião, vem do campo filosófico, do Sartre de L'être et le néant, no qual o pudor (que ele reduz à honte) é, na prática, a negação do $\operatorname{ser}^{10}$.

Uma reabilitação do pudor surge novamente das correntes fenomenológicas, personalísticas e espiritualistas, que o recolocam no centro da atenção. $\mathrm{O}$ pudor, como aparece na análise destes pensadores, é, na verdade, inato e não derivado, e tem um papel importantíssimo na construção da pessoa. Em todas as suas análises, destaca-se o lado obscuro, pelo qual, de alguma maneira, somos ameaçados.

Falou-se, às vezes, de uma "tirania do prazer" à qual nos sentimos, atualmente, condenados pelas solicitações da pressão de conformidade social veiculada pelos mass media e pela mentalidade deles decorrente. Para entender de que o pudor nos protege, é interessante refletir sobre o que consiste o "lado obscuro" do prazer (e, em certo modo, da dor).

O prazer, ainda que possa parecer o contrário, é uma realidade complexa, no que diz respeito tanto a sua compreensão, quanto ao modo de vivê-lo. Giorgio Nardone ${ }^{11}$ define-o como espaço vivo. Falar de "espaço" remetenos a uma esfera de união entre sentir e sentir-se, como uma "extensão",

10 "[A] redução negativa do pudor acentua-se em tais filões do existencialismo ateu, e sobretudo em Sartre, para o qual o pudor físico acaba por tornar-se não mais uma defesa, mas uma substancial recusa do ser. Após uma preliminar redução do pudor a vergonha (honte), o corpo é reduzido a instrumento atravé do qual, pelo olhar, a pessoa é 'expropriada' e por assim dizer 'engolida' pelo outro: mesmo se, com paradoxo apenas aparente, é exatamente o sentido de vergonha que torna o 'eu' consciente de si mesmo, no momento em que a honte revela ao ser a presença do outro e ao mesmo tempo o revela a si mesmo, através da consciência do ser 'olhado'. Destarte, 'eu sou vergonha daquilo que sou', pelo que 'a vergonha realiza então uma relação íntima comigo mesmo: com a vergonha, descubro um aspecto do meu ser'. Mas, porque todo encontro verdadeiro e profundo, não epidérmico e passageiro, entre as pessoas é irrealizável, porque toda relação é posta sob o signo da incomunicabilidade e mesmo da pretensão de cada um de tomar posse do outro, a vergonha assume um significado radicalmente negativo, constitui a prova final do inseparável abismo que divide as pessoas, a tal ponto que o eu 'sente a sua alienação e a sua nudez como uma degradação que deve assumir: é o sentido do famoso e souberam que estavam nus da Escritura'. A exposição ao olhar de outrem, revelada exatamente pelo pudor, torna-se assim uma culpa que nenhuma força, nem mesmo o amor sexual pode resgatar. A nudez é o modo através do qual cada um é 'engolido' visivelmente pelo outro, sem nunca poder ser aceito e amado como pessoa", ibidem, p. 215.

${ }^{11}$ G. NARDONE, Etica Generale, op. cit. 
quase matéria. É um affici ${ }^{12}$ que é auto-afecção, que remete a algo que nãome-é-estranho. O "vivo" faz lembrar que que tal "matéria", de certo modo, dá-se conta de si, percebe a si mesma.

Ora, este elemento (espaço) vivo, que sempre somos, coloca problemas. $\mathrm{O}$ prazer traz consigo, e em Aristóteles isto aparece com clareza, sempre um apeiron, um potencial "sempre-mais", indefinido (Sartre encontra-se nessa linha). Diríamos que é uma vertigem de infinito, um frêmito mau de apeiron.

Mas sua característica de affici kath'auton, para dizê-lo ainda com Aristóteles, fá-lo tendencialmente (não somente: mas também) fechado e solipsístico. Que outra coisa seria a tendência, notada em muitos lugares, da redução auto-erótica de quase todas as formas de prazer sexual que encontramos hoje?

E também sua característica de "duplo": é motor de ação, mas também perigo constante. É necessário, mas não pode ser acolhido sem alguma "precaução".

Esta é fundamentalmente a "situação de crise" na qual o pudor atua. Os autores que tomamos em consideração deslocam o acento da análise, ora aqui, ora sobre um outro ponto, mas todos evidenciam como o pudor de fato revela um horizonte de "perigo" do qual nos "protege".

Analisando o intervento do pudor, V. Soloviev ${ }^{13}$ mostra que ele acaba tendo a ver tanto com a esfera sexual quanto com comportamentos que vão contra exigências morais ${ }^{14}$. Em particular, Soloviev mostra como o pudor, fazendo o ser humano "envergonhar-se" daqueles comportamentos que no âmbito animal são a única forma de infinito que eles podem "conhecer" (a conservação da própria espécie através da união sexual, trasmitida por meio de indivíduos que desaparecem), revela que o ser humano não se reconhece em tal frêmito, mas percebe sua insuficiência e sua "vertigem". Aqui, diz Soloviev, não é importante o fato de que se envergonhe, mas aquilo de que se envergonha: da essência da vida animal, revelando, então, que ele é supra-animal, é supra-natural. Poderíamos dizer que o pudor faz o ser humano verdadeiramente ser humano.

O ser humano, por meio do pudor, recusa abandonar-se à cega força animal que, mesmo sendo nos animais uma forma de "plenitude", ele expe-

${ }^{12}$ Do verbo latino afficio ("mover-se", "ser tocado"). Normalmente usa-se com o ablativo (affici morbo: estar doente,). O prazer é um "espaço" no sentido de que é um affici: afetame, toca-me, mas não como algo que provém totalmente do que me é exterior; por isso, nesse sentido é um kath'auton. É algo que me afeta, mas que não experimento como totalmente estranho. Por isso traz consigo uma tendência ao solipsismo e sem algo "de fora" que o possa re-orientar, tende à implosão.

${ }^{13}$ V. SOLOVIEV, "Dal pudore sessuale alla vita morale", in T. ŠPIDLÍK, La spiritualità russa, Roma: Studium, 1981, pp. 72-118. O texto foi tirado da obra de Soloviev A justificação do Bem.

${ }^{14}$ Ibidem, p. 75. 
rimenta como insuficiente a seu desejo de sobrevivência eterna individual, e não por meio da sobrevivência da espécie ${ }^{15}$. O pudor revela-lhe - exatamente através da vergonha da sua animalidade - que ele é outro. Aponta para a força de eternidade presente na natureza, mas não se identifica com ela. Ele procura uma outra imagem de infinito com relação aos animais. $\mathrm{O}$ pudor protege-o desta força e também da ilusão de dominá-la (eternizandose através da arte, o kalon ergon, etc.). Não se trata do pudor da cópula em si, mas do significado que ela recebe no quadro da "animalidade".

É interessante notar que, na língua russa, a palavra que indica a pudicícia sexual, tchelomudrie significa "sabedoria integral". A sabedoria integral detecta uma integridade original do ser humano que foi perdida, ainda que não definitivamente, na atual situação. No ato sexual, sem a integridade original, tem-se somente uma "união de secreções", diz Soloviev, que tornam eterna a separação profunda, a desagregação da existência humana ${ }^{16}$.

Em K. Wojty $\mathrm{a}^{37}$, o pudor impede que tanto o próprio corpo quanto o corpo do outro sejam reduzidos a puro objeto de gozo sexual, uma espécie de "reificação sexual" que viola a inviolabilidade, o sacrário indisponível - a não ser somente a Deus - que é a pessoa humana. Wojty ${ }^{3}$ a sintetiza isto esplendidamente no recíproco dizer-ser "Não me toques, nem mesmo com o teu desejo interior", "Não posso tocá-la, nem mesmo com o meu desejo interior. Ela não pode ser objeto de gozo"18.

Por sua vez, E. Mounier ${ }^{19}$ vê no pudor algo que manifesta que "não há identidade entre a minha natureza corporal ou social objetivada e a minha existência" 20 . O perigo seria aqui ser reduzido apenas a aquilo que reconheço ser, mas no qual sinto não exaurir-me. Em Mounier, está claro que

\footnotetext{
${ }^{15}$ É sugestivo pensar em como este sentimento tão forte da alma russa será, exatamente neste ponto, forçado a cair com a chegada do comunismo. No "Virgílio" da épica soviética (M. Schokolov, O plácido Don) canta-se exatamente este ponto. O indivíduo morre, mas o Socialismo vai adiante graças ao sacrificio individual.

${ }^{16}$ Exemplar é a cena do filme "Não amarás" de K. Kieołowski [Decálogo, no 6], na qual se dá o primeiro encontro entre o jovem, que espiou pela janela até aquele momento, e a mulher observada. Ela o recebe e, logo nos "preliminares", o jovem tem uma ejaculação embaraçada. Ele enrubesce (vergonha) e a mulher, calma, olha para ele e diz: "Viu? O amor está todo nisso". Levanta-se e vai embora. A sexualidade "des-integrada", separada, absolutizada, sempre anda próxima da morte e da destruição. O jovem do filme citado tenta o suicídio. Mas, para permanecer no mundo cinematográfico, basta pensar em $O$ império dos sentidos de Nagisa Ôshima, $O$ último tango em Paris de Bernardo Bertolucci, Teorema de Pier Paolo Pasolini, etc. Em todos, há a explicitação da degeneração em morte de uma sexualidade des-pudorada.

${ }^{17}$ K. WOJTY£A, Amore e responsabilità, Torino: Marietti, 19803. [sobretudo a parte III, "La persona e la castità", pp. 103-151].

${ }^{18}$ Cf. ibidem, p. 131.

${ }^{19}$ E. MOUNIER, Introdução aos existencialismos, São Paulo: Duas Cidades, 1963: cap. V, "O tema do Outro", pp. 137-166.

${ }^{20}$ Ibidem, p. 160.
} 
tal sentimento de pudor não é um juízo negativo sobre a coisa em si: Não tenho vergonha do sexo, o problema surge se eu sou identificato apenas nos limites da sexualidade. Uma prova ex parte contraria é a perda do senso do pudor, que entrega inevitavelmente a pessoa à reificação, à redução a objeto de gozo, à "força animal": em uma palavra, a uma radical des-personalização. A redução do ser humano apenas à corporeidade é a fragmentação definitiva do ser humano, a sua entrega ao mundo "inferior" na acepção de Soloviev, a sua redução a puro objeto de gozo utilitarístico sexual (Wojtyäa).

\section{O pudor revela o que na verdade eu sou}

A função de guardião, porém, não é a principal. Em outras palavras, diríamos que o pudor não é somente um freio para o que chamamos de lado "obscuro" da sexualidade. O pudor revela tal lado, mas, ao mesmo tempo, e exatamente por isto, entrega-nos a "luz", revelando-nos o que somos.

Opondo-se à pura força animal, da qual fala Soloviev, o pudor não somente preserva o ser humano de cair nela, mas também revela que a dignidade humana é superior e permite experimentar o fato de que a integridade do ser humano está apenas escondida, mas não destruída. Através do amor verdadeiro, o ser humano busca a sua integridade que descobrimos, com Soloviev, não limitada ao campo da sexualidade.

A "força" que impulsiona em direção à conservação da espécie, e com a qual o ser humano, através do pudor, sente/descobre não identificar-se, revelando assim a sua radical alteridade, não age somente no nível psicofísico, mas tende a destruir todos os laços constitutivos do ser humano. Existe, de fato, dentro do ser humano, diz Soloviev ${ }^{21}$, uma tendência a ceder, de maneira servil e com um gozo "viscoso", à força cega e irreflexa. É um materialismo real. Mas existe também uma tendência a libertar-se de toda outra pessoa e a considerar-se em um estado de superioridade: é um verdadeiro egoísmo. Enfim, existe uma tendência soberba a renunciar à perfeição absoluta à qual se seria chamado, e a tornar a si mesmo como absoluto e incondicionado princípio da própria vida. É o ateísmo verdadeiro, prático. É um ateísmo perigosíssimo, porque, não somente elimina a possibilidade de relacionar-se com a vida integral que passa através de Deus, mas elimina até mesmo o desejo disso.

Existe uma unidade profunda, diz Soloviev, no ser hunmano: e isto é provado pelo fato de que é sempre o pudor que perpassa todos estes três campos "protegendo-os" e indicando assim aquela unidade e integridade que o ser humano é.

${ }^{21}$ Cf. V. SOLOVIEV, "Dal pudore sessuale alla vita morale", op. cit., p. 89s. 
Que acontece, então, quando, violando um destes campos, a raiz da consciência, ou seja, o pudor, segundo Soloviev, intervém avisando e revelando?

Eis por que é vergonhoso e por que a consciência acusa-nos por cada obra má, mesmo se apenas pensada. Não se viola algum princípio abstrato ou uma lei arbitrária. Trata-se, sim, de um passo falso cometido por nós: assim se produz um retardo, para nós e para os outros, no único caminho verdadeiro em direção ao único fim digno e desejado que é a restituição da vida eterna e incorruptível para todos. Tanto o pudor quanto a consciência ou o temor de Deus são expressões negativas para exprimir as condições necessárias para o fim divino-humano que é tanto real quanto elevado."22

Eis o que o pudor, que intervém em todas as três relações constitutivas do ser humano, revela: o fim teândrico, a divino-humanidade oferecida ao ser hunano em Cristo.

Para Wojtyª, o pudor é um reflexo natural da natureza inviolável da pessoa. No proteger contra a objetivação utilitarista para fins sexuais, o pudor revela, na pessoa, um núcleo inobjetivável e não utilizável.

O fato de esconder os valores sexuais, protegendo a própria interioridade, dizendo "não posso ser um objeto de gozo", e respeitando a interioridade da outra pessoa ("Tu não podes ser um objeto de gozo.") não exaure a revelação do pudor: ele, manifestando uma tendência a "provocar" o amor, manifesta-se como caminho de acesso ao amor.

Quando duas pessoas se amam, fenomenologicamente constata-se a absorção do pudor pelo amor. "Absorver" não é eliminar, e o pudor sempre corre o risco de ser reduzido a isso. "Absorver" significa, ao contrário, "que o amor utiliza os elementos do pudor sexual e sobretudo a consciência da justa proporção entre o valor da pessoa e o valor do sexo, proporção que o pudor revela ao homem e à mulher como natural e espontaneamente sentida" ${ }^{23}$.

Por que isto? Porque, no amor verdadeiro, o amante quer o bem da pessoa amada, e amar e reificar são contraditórios. Se há um, não pode haver o outro. Portanto, na presença do amor, a defesa natural abaixa-se, espontaneamente; é "absorvida" pelo amor. "...as relações sexuais dos esposos não são simplesmente uma forma de impudicícia tornada legal por força do ato de matrimônio, mas, ao contrário, são conformes às exigências internas do pudor (a menos que não sejam os esposos mesmos a torná-las impudicas com seu modo de realizá-las)"24.

${ }^{22}$ Ibidem, p. $96 \mathrm{~s}$.

${ }^{23}$ K. WOJTY£A, op. cit., p. 133.

${ }^{24}$ Ibidem. 
O fato, portanto, de viver o amor na sua "essência" impede de objetivar o outro, reduzindo-o somente ao plano do gozo. $\mathrm{O}$ amor tem esta força que permeia toda a relação, na vontade, etc., permitindo tomar o outro em toda a sua profundidade ${ }^{25}$.

O pudor "lembra-me que eu não sou apenas o instrumento passivo da natureza e dos seus fins. O homem poderia assim definir-se como um ser capaz de vergonha. Tenho vergonha, logo existo, no sentido mais pleno da palavra: existo como um ser transcendente, feito para permanentemente libertar-se de si próprio, das suas paixões, das suas ações, das suas perfeições paralisantes" ${ }^{\prime 2}$. Recorda-me e indica-me a minha integridade teândrica (Soloviev) como tarefa, desvela-me uma interioridade a ser guardada (Wojty ${ }^{3}$ a) e que não deve ser oferecida de modo impudico, sob o preço da reificação em "carne para exportação" 27.

Entendendo assim o pudor, podemos "recuperar" o prazer que chamávamos de affici kath'auton "mau". O pudor não é ocultamento (o que seria pura negação da realidade sexual), não é um "jogo" para tornar mais apetitoso o sexo. O pudor revela a sexualidade que se é e, ao mesmo tempo, faz com que ela se torne realidade de uma pessoa. O pudor revelanos que eu e tu não-somos-somente sexualidade ou corpo de prazer: isto foi visto em todos os autores que apresentamos até aqui. O conter-se ("Não posso tocar-te nem mesmo com o olhar") diante do outro implica e afirma uma diferença. O pudor diz: "Respeito!", é um limite que não posso ultrapassar, dito de outra forma, é domínio.

No duplo movimento wojty3iano (no qual o pudor guarda e "provoca" o amor), o pudor oferece a própria sexualidade, entrega-a ao outro como boa, e o faz pela primeira vez. É um dizer "é bom que tu sejas (também)

${ }^{25}$ Permanece sempre um perigo. O "temor" relacionado aos valores sexuais diminui com a gradual percepção de que não provoca unicamente desejo sexual. Poder-se-ia então pensar que o sentimento de amor, que tem o poder de absorver a vergonha, possa conferir o direito às relações sexuais. Mas isso é errado, porque sentimento de amor é bem diferente do verdadeiro amor de vontade. Este último implica uma escolha recíproca das pessoas, em vistas a uma relação estável, duradoura, etc. É a dimensão objetiva do amor esponsal. Por isto, é necessário educar o pudor sexual: a componente "desordenada" sempre está à espreita. Portanto, a absorção da vergonha não permanece apenas no nível emotivo-afetivo. A vergonha pode ser "absorvida somente por um amor verdadeiro, o qual, afirmando o valor da pessoa, procura, com todas as suas forças, o bem mais completo do próprio objeto", ibidem, p. 135.

${ }^{26}$ E. MOUNIER, op. cit., p. 161.

27 "Se o pudor é força, a impudicícia é fraqueza, espiritual e metafísica. Aquilo que reduz a pessoa a corporeidade desconhece o seu sentido profundo e a sua dimensão metafísica: neste sentido, a obscenidade é uma culpa no sentido metafísico ainda mais do que no sentido moral. Como releva Sartre, 'o obsceno aparece quando o corpo adota atitudes que o despem totalmente dos seus atos e que revelam a inércia da sua carne'. A impudicícia é tomar o outro, e aceitar ser tomado pelo outro, na 'inércia da carne', na recusa da globalidade da vida pessoal”, G. CAMPANINI, op. cit., p. 221. 
assim", ou seja, no pudor surge - e é reconhecido - aquele para o qual "até mesmo" a sexualidade é uma coisa boa.

Mas mais importante e decisivo é o fato de que o pudor revela o corpo como indício de uma interioridade. Isto significa que (atenção: somente no final da reflexão o dizemos e nunca deveríamos tomá-lo como ponto de partida - o que é primeiro na intenção é último na execução!) tudo que é relativo e alude ao prazer não é mais aquele espaço-vivo de auto-affici que dizíamos em precedência, mas remete e alude a uma interioridade a ser guardada.

\section{Conclusão}

O pudor revelou-se a nós como um verdadeiro "pastor". Ele guarda o valor da pessoa, protegendo-a de uma dissipação não apenas inútil, mas também devastante. Impede a reificação e o deslizar na escravidão da tendência, sempre presente no ser humano, à imobilidade da matéria iner$\mathrm{te}^{28}$, sob o aspecto da perda daquilo que é próprio da pessoa humana: a sua dignidade, a sua inviolabilidade, a sua integridade, a sua vocação teândrica.

Ao mesmo tempo, vimos que, protegendo, o pudor indica a estrada, tornase indicador de caminho rumo ao amor. O pudor, escreve J. Guitton, "é um invólucro diáfano posto pela natureza ao redor dos sentidos, para evitar que o espírito venha, demasiadamente cedo, a ter contato com a vida, para dar-lhe um modo de habituar-se pouco a pouco". Assim o pudor não é somente um mecanismo de proteção, mas é também "órgão do desenvolvimento espiritual, o auxiliar da duração" e o "mediador da unidade da alma com o corpo ${ }^{29}$.

Ateão vê Artêmis nua, banhando-se em um rio depois da caça. A pena é terrível: será condenado a fugir, eternamente perseguido por um bando de cães, que o alcançarão e o dilacerarão. Mas ele renascerá do seu sangue e novamente recomeçará a fugir, perseguido. Como a dizer: não se pode superar o limite, a guarda da castidade, sem ser devastado pela força da sexualidade, sem limites.

\footnotetext{
${ }^{28}$ Assim pensa a psicanálise, segundo uma iluminada análise de H. Pellegrino: "A luta entre Eros e Tanatos - vida e morte - se decide dentro de cada um de nós, a cada instante. Por nascermos prematuros, incompletos, sem equipamento instintivo capaz de nos costurar com solidez ao mundo, sofremos a permanente saudade de ser pedra, a nostalgia de um sono sem retorno, regido por estatuto que nos trascenda e que não podemos desobedecer - ou transgredir", H. PELLEGRINO, "Édipo e liberdade", in idem. A burrice do Demônio, Rio de Janeiro: Rocco, 1988, p. 97.

${ }^{29}$ Cf. J. GUITTON, L'amour humain. Suivi de deux essais sur "Les relations de famille" et sur "Le démon du midi". Paris: Aubier, Éd. Montaigne, 1955, chap. IV: "La crise initiale”, pp. 65-99.
} 
Por isto Guitton fala de pudor como órgão do desenvolvimento espiritual, que não permite queimar as etapas, saltar as passagens necessárias, mas habitua, pouco a pouco, ao contato com as realidades de si mesmo.

A falta de pudor de quem se oferece à objetivação transforma-se na negação da própria dignidade. Nada é tão reificante como o olhar impudico, de-gradação de inevitáveis conseqüências.

O texto de Guitton convida-nos também a pensar que o pudor é algo que está ligado a uma certa temporalidade, ainda que estruturalmente faça parte da pessoa, e deva, portanto, ser educado, exercitado, ajudado no cumprir sua função de mediador entre a alma e o corpo.

Não cremos que a educação para o pudor seja algo caduco para os nossos dias. Contudo, estamos convencidos certamente de que não possa ser o primeiro assunto de uma conversa com os jovens. Com uma prévia operação de ecologia mental quanto à mentalidade massmedial, e uma relativa desintoxicação, pensamos, porém, que seja um caminho que possa valer a pena percorrer.

(Tradução do original italiano por Claudio Paul SJ)

Massimo Pampaloni SJ é Mestre e Doutorando em Ciências Eclesiásticas Orientais na área da Teologia Patrística pelo Pontifício Instituto Oriental (Roma). Obteve o título de Bacharel em Filosofia pelo Istituto di Studi Filosofici Aloisianum de Pádua (Itália) e em Teologia pelo Centro de Estudos Superiores da Companhia de Jesus (Belo Horizonte). É autor de alguns artigos publicados pelas revistas Convergência e Perspectiva Teológica.

Endereço: Piazzale Aldo Moro, 1 00185 Roma Itália

e-mail: pampaloni.m@gesuiti.it 


\section{Coleção CES}

A Coleção CES reúne estudos de filosofia e cultura, teologia e religião, sob a responsabilidade do Centro de Estudos Superiores da Companhia de Jesus.

\section{Títulos Publicados:}

1. A Palavra se fez livro Johan Konings

2. Cenários da Igreja, $2^{a}$ ed.

J. B. Libanio

3. Teologia da espiritualidade cristã

Danilo Mondoni

4. Igreja contemporânea - encontro com a modernidade J. B. Libanio

5. Conhecimento afetivo em Santo Tomás Paulo Meneses

6. Experiência mística e filosofia na tradição ocidental Henrique C. de Lima Vaz

7. História da Igreja na Antiguidade Danilo Mondoni

8. Matrimônio - Aliança - Reino Francisco Taborda

9. Ecologia e criação - Resposta cristã à crise ambiental José Roque Junges

10. A arte de formar-se

João Batista Libanio

11. Folhas de Outono

Fernando Bastos de Ávila

12. Deslocamentos da teologia - mutações do cristianismo Carlos Palacio

13. Um incendido desejo das Índias Marina Massimi

14. Teologia em diálogo Bruno Forte

15. Filosofia e método Emídio Fontenele de Brito / Luiz Harding Chang (orgs.)

16. Teologia e Pastoral Johan Konings

17. Filosofia e Política

Miriam Campolina D. Peixoto / Washington da Silva Paranhos (orgs.)

18. Mysterium Paschale - A quenose de Deus segundo Hans Urs von Balthasar Clarita Sampaio Mesquita Ribeiro

Edições Loyola - Cx. P. 42.355 - CEP 04299-970 São Paulo e-mail: vendas@loyola.com.br 